\title{
Reduction of bile acid loss in cystic fibrosis by dietary means
}

\author{
CHRistine A. SMAlley, G. A. BROWN, M. E. T. PARKES, HAZEL TEASE, \\ VALERIE BROOKES, AND CHARLOTTE M. ANDERSON
}

From the Institute of Child Health, University of Birmingham, and Birmingham Children's Hospital

SUMMARY On a 'normal' diet increased faecal bile acid excretion was found in 14 of 16 children with cystic fibrosis who had steatorrhoea, but excretion was normal in 2 such children without steatorrhoea. The 16 children with steatorrhoea took 3 regimens of diet and therapy: a 'normal' diet with pancreatic enzyme supplements, a diet of reduced long-chain triglycerides with added mediumchain triglycerides, and the same diet with added pancreatic enzyme supplements. On each of these three regimens steatorrhoea and faecal bile acid loss were significantly less than on no treatment, with the lowest excretions occurring on the diet of reduced long-chain triglycerides with added medium-chain triglycerides and pancreatic enzyme supplements. Although a reduction in steatorrhoea was nearly always accompanied by a decrease in bile acid excretion, the initial bile acid loss was very variable and could not be predicted for any given degree of steatorrhoea. This suggests that at least one other factor, possibly liver disease or bile acid pool size, influences bile acid loss in the faeces.

Excessive loss of bile acids in the faeces has been shown to occur in cystic fibrosis (CF) patients: neither this loss nor the steatorrhoea resulting from pancreatic insufficiency is eliminated by pancreatic enzyme preparations given with their meals (Weber et al., 1973, 1976; Goodchild et al., 1975). With excessive bile acid loss a compensatory increase in bile acid synthesis occurs in the liver but, if excretion is sufficiently great, depletion of the bile acid pool may result (Weber et al., 1972; Watkins et al., 1974). If the postprandial duodenal bile acid concentration then fails to reach the critical micellar concentration, digestion of fat will be further impaired, leading to an increase in steatorrhoea resistant to further enzyme replacement therapy. There may be good nutritional grounds therefore for reducing the bile acid loss in CF.

It has been suggested (Goodchild et al., 1975) that this increased loss of bile acids may cause or exacerbate the characteristic form of progressive multifocal biliary cirrhosis of the liver found in CF (Webster and Williams, 1953; di Sant' Agnese and Blanc, 1956). Small areas of fibrosis together with small bile duct plugging are found at necropsy in nearly all children dying after the age of one year (Bodian,

Received 4 November 1977
1952) but cirrhosis is manifest clinically only in about $10 \%$ of children with CF and particularly in the older ones (Shwachman et al., 1965). In some, portal hypertension also develops (Tyson et al., 1968). The aetiology of this liver disease is obscure but the excessive loss of bile acids could be a contributing factor. There is some inferential evidence for this hypothesis. About $15 \%$ of $\mathrm{CF}$ patients retain sufficient pancreatic enzyme secretory function to prevent steatorrhoea. As far as we can ascertain from wide inquiry and from clinical experience, portal hypertension and cirrhosis are not seen in such patients without steatorrhoea and who have been shown by Weber et al. (1976) and by ourselves not to be losing bile acids. Furthermore, hepatic fibrosis is associated with bile acid loss and altered bile acid metabolism in adults with ileal bypass for morbid obesity (Bagheri et al., 1974; Sherr et al., 1974). Reduction of the bile acid loss in CF may have important clinical implications.

Weber et al. (1973) suggested that unhydrolysed triglyceride in the small bowel might be responsible for malabsorption of bile acids. We have reduced steatorrhoea substantially in CF patients by dietary changes in addition to the administration of pancreatic enzyme preparations and have observed the related losses of bile acids in the faeces. 


\section{Patients}

Eighteen patients with CF were studied (Table). Diagnoses were based on characteristic clinical features and confirmed by sweat sodium concentrations $>60 \mathrm{mmol} / \mathrm{l}$ determined on sweat collections $>100 \mathrm{mg}$ in weight. Case 17 was investigated while undergoing the initial diagnostic investigations. The remainder were attending the CF clinic and were selected using the following criteria: patient and parents were keen to participate; they lived reasonably near to the hospital; and the patient was adequately toilet trained to ensure complete stool collections.

Cases 17 and 18 did not have steatorrhoea. Pancreozymin-secretin stimulation in these 2 patients (Hadorn et al., 1968) had produced normal duodenal enzyme concentrations but no bicarbonate response and very low volumes of viscous juice as is customary in such CF patients. The remaining 16 patients all had steatorrhoea, and consisted of 6 boys and 10 girls whose ages ranged from $3 \cdot 0-11 \cdot 7$ years, mean age $7 \cdot 4$ years. Case 15 , a boy of 11 years, had liver disease, manifest clinically as an enlarged firm liver and abnormal liver function tests (aspartate transaminase $300 \mathrm{IU}$, alanine transaminase $147 \mathrm{IU}, 5 \mathrm{NT}$ $46 \mathrm{IU})$. Cases 11 and 12 were siblings, as were 3 and 9. Case 11 also had diabetes mellitus.

Control data for faecal bile acid excretion were determined in our own laboratory from 11 healthy children, 5 boys and 6 girls, aged from 6 months to 13.8 years, mean age 6.3 years (Goodchild $e t$ al., 1975).

\section{Methods}

Design of study. Cases 17 and 18, who did not have steatorrhoea, each provided a single 3-day stool collection while taking their normal diet. All 16 patients with steatorrhoea were studied entirely at home (under the supervision of C.A.S.). Four different regimens of diet and therapy were designated A, B, C, and D.

Regimen $A$ was the patient's 'normal' diet with pancreatic enzymes omitted. 'Normal' indicated the diet usually taken by the child-a self-selected diet with variable fat restriction. This diet was recorded in detail by the parent. Fat content calculated from

Table Faecal fat and bile acid excretion during 4 regimens of diet and pancreatic enzyme therapy

\begin{tabular}{|c|c|c|c|c|c|c|c|c|c|}
\hline \multirow[t]{2}{*}{ Case no. } & \multirow[t]{2}{*}{ Age (years) } & \multicolumn{2}{|c|}{$\begin{array}{l}\text { Regimen } A \\
\text { Normal diet, no enzymes }\end{array}$} & \multicolumn{2}{|c|}{$\begin{array}{l}\text { Regimen } B \\
\text { Normal diet, plus enzymes }\end{array}$} & \multicolumn{2}{|c|}{$\begin{array}{l}\text { Regimen } C \\
\text { Reduced LCT plus } M C T \text {, } \\
\text { no enzymes }\end{array}$} & \multicolumn{2}{|c|}{$\begin{array}{l}\text { Regimen } D \\
\text { Reduced LCT plus MCT } \\
\text { plus enzymes }\end{array}$} \\
\hline & & $\begin{array}{l}\text { Fat } \\
(m m o l / d a y)\end{array}$ & $\begin{array}{l}\text { Bile acid } \\
\text { ( } \mathrm{mmol} / \mathrm{kg} \\
\text { per day })\end{array}$ & $\begin{array}{l}\text { Fat } \\
(\mathrm{mmol} / d a y)\end{array}$ & $\begin{array}{l}\text { Bile acid } \\
\text { ( } \mu \text { mol } / k g \\
\text { per day) }\end{array}$ & $\begin{array}{l}\text { Fat } \\
(\mathrm{mmol} / \text { day })\end{array}$ & $\begin{array}{l}\text { Bile acid } \\
(\mu \mathrm{mol} / \mathrm{kg} \\
\text { per day) }\end{array}$ & $\begin{array}{l}\text { Fat } \\
(\mathrm{mmol} / \mathrm{day})\end{array}$ & $\begin{array}{l}\text { Bile acid } \\
\text { ( } \mu \mathrm{mol} / \mathrm{kg} \\
\text { per day }\end{array}$ \\
\hline \multicolumn{10}{|c|}{ (a) Patients with steatorrhoea } \\
\hline 1 & $\mathbf{3 \cdot 0}$ & 63 & 97 & 86 & 62 & 73 & 63 & 43 & 47 \\
\hline 2 & $3 \cdot 2$ & 84 & 73 & 21 & 46 & 56 & 62 & 28 & 38 \\
\hline 3 & $4 \cdot 8$ & 48 & 49 & 47 & 23 & 49 & 42 & $\begin{array}{l}20 \\
19\end{array}$ & 18 \\
\hline 4 & $5 \cdot 0$ & 76 & 95 & 24 & 108 & 36 & 50 & 45 & 80 \\
\hline 5 & $5 \cdot 1$ & 43 & 84 & 39 & 68 & 44 & 39 & 19 & 32 \\
\hline 6 & $5 \cdot 3$ & 113 & 57 & 66 & 68 & 100 & 19 & 70 & 38 \\
\hline 7 & $5 \cdot 7$ & 77 & 56 & 66 & 88 & 39 & 41 & 37 & 13 \\
\hline 8 & $5 \cdot 8$ & 105 & 79 & 42 & 65 & 39 & 51 & 31 & 41 \\
\hline 9 & $8 \cdot 5$ & 69 & 37 & 63 & 24 & 72 & 113 & 26 & 16 \\
\hline 10 & $8 \cdot 6$ & 151 & 112 & 82 & 86 & 62 & 80 & 78 & 32 \\
\hline 13 & $10 \cdot 5$ & 129 & 149 & 82 & 115 & 86 & 73 & 50 & 49 \\
\hline 14 & 10.9 & 161 & 130 & 134 & 69 & 58 & 75 & - & - \\
\hline 15 & 11.0 & 100 & 14 & 66 & 34 & 55 & 14 & 37 & 18 \\
\hline 16 & $11 \cdot 7$ & 43 & 69 & 52 & 34 & 25 & 43 & 23 & 18 \\
\hline $\begin{array}{l}\text { Mean } \\
\quad \pm 1 \mathrm{SD}\end{array}$ & $7 \cdot 4$ & $\begin{array}{l}103 \\
\pm 53\end{array}$ & $\begin{array}{l}74 \\
\pm 37\end{array}$ & $\begin{array}{c}76 \\
\pm 47\end{array}$ & $\begin{array}{c}62 \\
\pm 29\end{array}$ & $\begin{array}{l}68 \\
\pm 40\end{array}$ & $\begin{array}{l}56 \\
\pm 26\end{array}$ & $\begin{array}{l}43 \\
\pm 20\end{array}$ & $\begin{array}{l}35 \\
\pm 18\end{array}$ \\
\hline \multirow{2}{*}{\multicolumn{4}{|c|}{$\begin{array}{l}\text { Statistical } \\
\text { comparisons }\end{array}$}} & \multirow[t]{3}{*}{$\begin{array}{l}\mathbf{B}<\mathbf{A} \\
\mathbf{P}<0.002\end{array}$} & $\begin{array}{l}\mathbf{B}<\mathbf{A} \\
\mathbf{P}<0.05\end{array}$ & $\begin{array}{l}C<A \\
P<0.005\end{array}$ & $\begin{array}{l}\mathbf{C}<\mathbf{A} \\
\mathbf{P}<0.05\end{array}$ & \multirow[t]{3}{*}{$\begin{array}{l}D<A \\
P<0.0005 \\
D<C \\
P<0.005\end{array}$} & $\begin{array}{l}\mathrm{D}<\mathrm{A} \\
\mathrm{P}<0.0005 \\
\mathrm{D}<\mathrm{C} \\
\mathrm{P}<0.02\end{array}$ \\
\hline & & & & & & & & & \\
\hline $\begin{array}{l}17 \\
18\end{array}$ & $\begin{array}{l}0 \cdot 5 \\
6 \cdot 3\end{array}$ & $\begin{array}{r}12 \\
7\end{array}$ & $\begin{array}{l}15 \\
19\end{array}$ & & & & & & \\
\hline \multicolumn{10}{|c|}{ (c) Normal values (mean age and levels in 11 control subjects) } \\
\hline Mean \pm 1 SD & & \pm 4 & \pm 3 & & & & & & \\
\hline
\end{tabular}


the diet record varied from $1 \cdot 2 \mathrm{~g}-5 \cdot 6 \mathrm{~g}$ fat $/ \mathrm{kg}$ body weight per day.

Regimen $B$ was the same 'normal' diet plus pancreatic enzymes of which each child took his/her usual prescribed dose. This had previously been found by the parent and child to be most effective in reducing bowel symptoms on the 'normal' diet. The enzyme preparations* used were Pancrex V powder (4 patients), Pancrex $V$ tablets (1 patient), Pancrex V forte tablets ( 9 patients), and Nutrizym (2 patients).

Regimen $C$ was a diet of reduced long-chain triglyceride (LCT) with added medium-chain triglyceride (MCT) but without pancreatic enzymes.

Regimen $D$ was the same reduced LCT plus MCT diet with pancreatic enzyme added.

The fat content of the reduced LCT plus MCT diet was calculated for each child. It contained one-third of the original LCT content, the remaining twothirds being replaced by an equal weight of MCT. The latter was given to provide additional calories and to make the diet more palatable. The MCT products* used were MCT (1) Trufood milk and Alembicol D oil for cooking purposes.

The dose of pancreatic enzymes taken with regimen $\mathrm{D}$ was selected by parent and child as the most effective dose with that particular diet. Most chose a dose approximately one-third to one-half of the usual one. 15 of the 16 children took all 4 regimens. Case 14 took regimens $A, B$, and C only.

The experimental periods were consecutive as far as possible and conducted in any order which suited the family, provided either regimen A or B preceded C or D, to permit calculation of the content of the reduced LCT plus MCT diet. All other therapy was kept constant during the four periods, except in one child (Case 8) where a change of antibiotics was necessary. The experimental period for each regimen lasted a minimum of 5 days, and was on average of 8 days' duration. A 72-hour faecal collection was made from each child at the end of each period, specimens were placed in insulated containers supplied to the patients' homes and kept cold with ice-bags. On completion of a 72-hour collection $(3 \times 24$ hours) the containers were delivered to the laboratory and the stools stored at $-18^{\circ} \mathrm{C}$ until analysed.

Laboratory. Each 24-hour stool collection was homogenised with three times its own weight of water in a Colworth Stomacher 3500 . Weight aliquots of homogenate were taken for immediate analysis or were stored at $-18^{\circ} \mathrm{C}$ until analysed.

*Enzyme preparations: Pancrex: Paines and Byrne Ltd, England. Nutrizym: E. Merck Ltd, England. MCT (1) Trufood milk: Cow \& Gate, England. Alembicol D oil: E. J. R. Lovelock Ltd, England.
Faecal fat analysis. Total faecal fat was measured by the method of van de Kamer et al. (1949) using the modification of Anderson et al. (1952) with further modification at the petroleum ether-fatty acid extraction step to ensure extraction of mediumchain fatty acids. Increasing the water content of the ethanol-water phase from $30 \%$ to $60 \%$ before extraction of fatty acids and extracting twice with petroleum ether produced recoveries of mediumchain fatty acids added to homogenates of not less than $93 \%$ (G. A. Brown, unpublished, 1975). The extracted fatty acids were also isolated by thin-layer chromatography, methylated using the technique of Fosbrooke and Tamir (1968) for conservation of medium-chain fatty acids and separated on a Pye 104 gas chromatograph.

Faecal bile acid analysis. The total $3 \alpha-\mathrm{OH}$ bile acid content of the homogenates was measured by an enzyme method (Iwata and Yamasaki, 1964) using $3 \alpha$-hydroxysteroid dehydrogenase, similar to that described by Murphy (1975) but modified by the addition of a thin-layer chromatographic purification step for elimination of neutral lipids (Weber et al., 1972).

Statistical evaluation. Significance of differences between fat and bile acid excretions on the four dietary regimens was determined using the paired t-test.

\section{Results}

The results of fat and bile acid excretion on the four regimens, together with the control data and statistical evaluations, are given in the Table and in Fig. 1. Bile acid excretion was normal in the 2

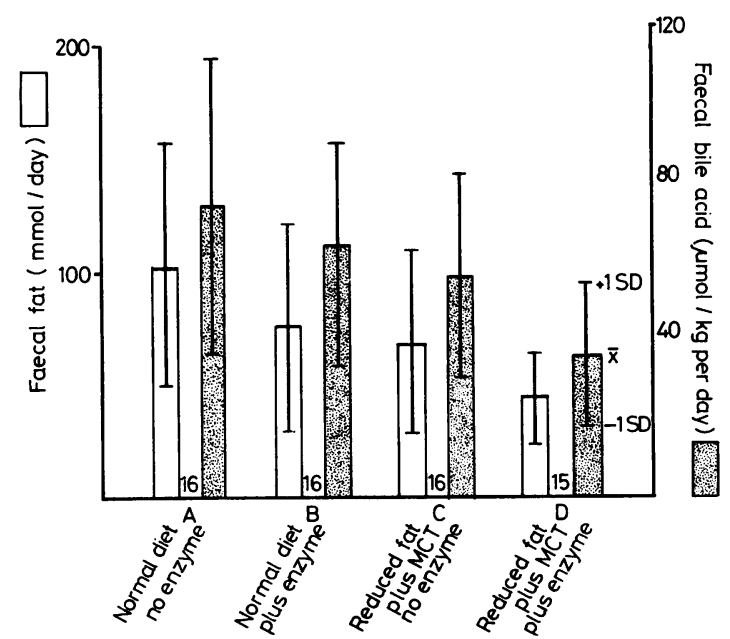

Fig. 1 Mean and range of faecal fat and bile acid excretion on 4 regimens of diet and therapy. 
patients who did not have steatorrhoea but greater then normal in the other 16, all of whom showed substantial steatorrhoea (mean coefficient of fat absorption $58 \%$, varying from $42 \%$ to $84 \%$ ) on a normal diet without pancreatic extracts-regimen A. On this regimen bile acid levels were nearly all above those of the controls but they varied widely $(14 \cdot 0$ $149.0 \mu \mathrm{mol} / \mathrm{kg}$ per day) and did not correlate with the individual faecal fat levels. In the group as a whole (Fig. 2) there appears to be no correlation between faecal fat and bile acid levels. However, Fig. 1 shows clearly that when faecal fat is reduced as in regimens $\mathrm{B}, \mathrm{C}$, and $\mathrm{D}$, bile acid excretion also falls.

Pancreatic extracts added to a 'normal' diet (regimen B) brought about a significant reduction of both faecal fat and bile acids, this reduction being

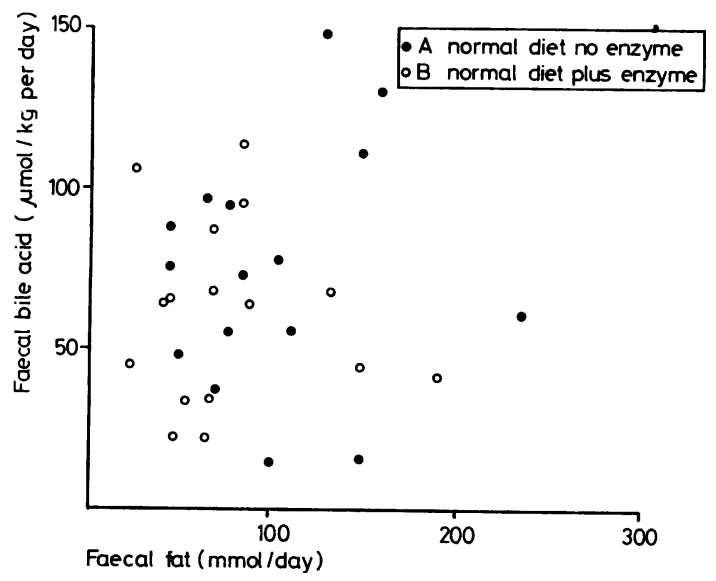

Fig. 2 Faecal bile acid excretion related to faecal fat excretion on regimens $A$ and $B$. similar to that occurring on the reduced LCT + MCT diet without pancreatic enzymes (regimen C). The reduction was greatest on the reduced LCT diet plus MCT and pancreatic enzymes (regimen D), this being highly significant compared with no treatment. On regimen $D, 5$ patients had bile acid values within the control range. In all of these faecal fat was below $8 \mathrm{~g} /$ day $(28 \mathrm{mmol})$. Fig. 3 compares the individual data for fat and bile acid losses on regimens $A$ and $D$, and shows that on regimen $D$ variation in fat and bile acid levels is also greatly reduced.

Only 2 patients showed no reduction in bile acid excretion on regimen $\mathrm{D}$ despite decreases in steatorrhoea. One of these was Case 15 who had abnormal liver function tests. He was also the only patient with consistently low faecal bile acid excretions, three of the bile acid values being within the control range while the fourth was only slightly raised.

Excellent absorption of MCT was evident from the results of gas liquid chromatographic analysis of faecal fatty acids from regimens $C$ and $D$ in which medium-chain fatty acids were never more than $5 \%$ of the total fatty acids present, although MCT was $67 \%$ of the total fat intake on these two regimens.

\section{Discussion}

Our findings confirm previous observations that faecal bile acid loss is almost always raised in CF children who have steatorrhoea. In 2 patients without steatorrhoea we found bile acid excretions within control limits, and this has also been found by other workers (Weber et al., 1976). Normal excretion in patients retaining some pancreatic function suggests that the excessive bile acid loss usually found in CF

is not a primary manifestation of the basic defect but is in some way associated with the fat malabsorption.

When considering the data as a whole from the group with steatorrhoea, bile acid loss varied enormously and did not correlate with the degree of steatorrhoea. However, in the individual patient, when steatorrhoea was reduced by therapy or dietary alteration, there was almost always a concomitant reduction in faecal bile acids. This suggests that bile acid losses are related primarily to the degree of steatorrhoea but are modulated by other factors, perhaps those which reduce the quantity of bile acids entering the duodenum, such as reduction in bile acid pool size. Such a reduction might very well result from increased losses occurring over very long periods. Goodchild and co-workers (1975) found that bile acid losses decreased with age and suggested that chronic increased loss would lead to decreased pool size and eventually to reduced secretion into the duodenum. Roller and Kern (1977) found near normal faecal bile acid values in 8 older CF children (mean age 18 years), a result which is consistent with Goodchild's (1975) observation of lower values in older patients, and might also be interpreted as evidence for pool size reduction. Direct evidence for this supposition has now been produced by pool size measurements (Watkins et al., 1974; Weber et al., 1975); synthesis rates and fractional turnover rates have been reported to be raised while pool size is reduced in some patients.

The liver's ability to synthesise bile acids at the required rate may be further compromised by liver disease. Goodchild et al. (1975) found that some of the lowest faecal bile acid values were from patients with liver disease, manifest as an enlarged firm liver, abnormal biochemical liver function tests, and in one patient portal hypertension with oesophageal varices. Such patients may no longer be able to synthesise sufficient bile acids to replace faecal losses. Case 15, who had consistently low faecal bile acid values, was also the only patient with recognised liver disease.

Weber et al. $(1973,1976)$ reported a significant correlation between faecal fat and bile acid excretion in their group of patients, a finding which is at variance with our results. We noted that the mean fat excretion in their patients was considerably lower than in ours. In 1973, they found a mean faecal fat value of $13.0 \mathrm{~g} /$ day $(46 \mathrm{mmol} /$ day $)$ in 24 untreated CF patients, and in 1976 a mean value of $17.0 \mathrm{~g} /$ day $(60 \mathrm{mmol})$ in 43 untreated patients. In contrast, the mean fat excretion in our patients on regimen $A$ was much higher at $103 \mathrm{mmol} / \mathrm{day}$. If steatorrhoea was consistently less severe in the patients described by Weber et al. (probably due to their practice of more consistent restriction of dietary fat) the bile acid pool size in their patients might have been less depleted, thus removing or reducing one of the possible factors influencing bile acid excretion.

MCT was used in our study to make a low LCT diet more palatable and to maintain the calorie content (Leyland et al., 1969; Gracey et al., 1970). When dietary LCT is replaced by MCT, steatorrhoea is reduced (Anderson and Burke, 1967) because intraluminal hydrolysis of MCT is not essential for its absorption (Hofmann, 1968). In our patients on regimens $\mathrm{C}$ and $\mathrm{D}$, faecal fatty acid analysis showed only negligible quantities of MCT. The MCT products were well tolerated by the children. Furthermore, nearly all the children or their parents commented favourably on the improved nature of the stools while on the MCT and reduced LCT diet, the stools being generally less bulky, less offensive, more formed, and less frequent. Restriction of LCT in the diet however proved the greatest hardship, particularly for the older children. It was less of a problem for the younger ones who were not so accustomed to a freer diet.

The cost of the MCT products per week was, on average, slightly less than the cost of the usual dose of pancreatic enzymes. On the MCT plus enzyme diet (regimen D) total cost was therefore somewhat greater, despite the reduced enzyme dosage. In the 5 children who were taking very high initial doses of pancreatic enzymes, the cost of MCT products plus lower dose of enzymes was actually less expensive than their usual dose of enzymes.

We did not give a reduced LCT diet without adding MCT and we cannot be certain whether the observed decrease in bile acid excretion on our modified diet was due entirely to the reduced LCT content, or in part due to the presence of MCT. Redinger et al. (1973) studied the effects of various diets on bile salt synthesis, secretion, and pool size of rhesus monkeys with exteriorised enterohepatic circulations and found that all three were reduced when MCT (tricaprylin, C:8) was fed, or when a fatfree diet was given. It has also been reported (Ansanelli and Capotorti, 1970) that dietary LCT is better absorbed in the presence of MCT. Such interactions make it impossible to predict the likely effect of LCT restriction on bile acid excretion when used without MCT addition.

We were concerned that dietary protein and its absorption might also be decreased by reduction of both dietary LCT and pancreatic enzymes in regimen $D$. By reducing LCT in the diet, many protein-containing foods may be excluded; furthermore the quantity of pancreatic enzyme used with the modified diet was considerably less than was usually taken and might have been insufficient for adequate protein digestion. We are therefore 
examining dietary protein intake and its absorption. Preliminary results suggest that the total protein intake on the reduced LCT diet with added MCT was not significantly different from that of the normal diet and that nitrogen absorption (in the presence of pancreatic enzymes) was actually improved. Faecal nitrogen excretions will be the subject of a separate communication.

We conclude that bile acid malabsorption can be reduced in the CF patient by reducing steatorrhoea. The most effective regimen in this study was the low LCT diet with added MCT and pancreatic enzymes. It produced normal or near normal bile acid excretions in many of our patients. Regimen D appears suitable for longer term use. It would be acceptable, especially to younger patients, and is not prohibited by cost. Considering the clinical implications of chronic excessive bile acid loss, a controlled trial of such a regimen in the long-term management of CF could be justified.

We thank the Cystic Fibrosis Research Trust for financing this study, and the patients and parents for their extreme goodwill and co-operation.

\section{References}

Anderson, C. M., and Burke, V. (1967). Medium chain triglyceride feeding in cystic fibrosis. Proceedings of the 4th International Conference on Cystic Fibrosis of the Pancreas (Mucoviscidosis), Part I, pp. 326-331. Ed. by E. Rossi and E. Stoll. Karger, Basel.

Anderson, C. M., Frazer, A. C., French, J. M., Gerrard, J. W., Sammons, H. G., and Smellie, J. M. (1952). Coeliac disease-gastroenterological studies and effect of dietary wheat flour. Lancet, 1, 836-842.

Ansanelli, V., and Capotorti, M. A. (1970). Influenza degli acidi grassi a media catenia sull'assorbimento intestinale di altri acidi grassi in soggetti mucoviscidotici alimentati con dieta mista. Fracastoro, 63, 637-641.

Bagheri, S. A., Barbato, T. L., Ferguson, D. J., and Boyer, J. L. (1974). The development of Laennec's cirrhosis in asymptomatic patients with small bowel bypass for massive obesity. (Abst.) Gastroenterology, 66, 878.

Bodian, M. (1952). Fibrocystic Disease of the Pancreas: a Congenital Disorder of Mucus Production. Heinemann, London.

di Sant'Agnese, P. A., and Blanc, W. A. (1956). A distinctive type of biliary cirrhosis of the liver associated with cystic fibrosis of the pancreas. Pediatrics, 18, 387-409.

Fosbrooke, A. S., and Tamir, I. (1968). A modified method for the preparation of methyl esters of a mixture of medium-chain and long-chain fatty acids. Clinica Chimica Acta, 20, 517-522.

Goodchild, M. C., Murphy, G. M., Howell, A. M., Nutter, S. A., and Anderson, C. M. (1975). Aspects of bile acid metabolism in cystic fibrosis. Archives of Disease in Childhood, 50, 769-778.

Gracey, M., Burke, V., and Anderson, C. M. (1970). Medium chain triglycerides in paediatric practice. Archives of Disease in Childhood, 45, 445-452.
Hadorn, B., Johansen, P. G., and Anderson, C. M. (1968). Pancreozymin secretin test of exocrine pancreatic function in cystic fibrosis and the significance of the result for the pathogenesis of the disease. Canadian Medical Association Journal, 98, 377-385.

Hofmann, A. F. (1968). Intraluminal factors in the absorption of glycerides. Medium Chain Triglycerides, pp. 9-19. Ed. by J. R. Senior. University of Pennsylvania Press, Philadelphia.

Iwata, T., and Yamasaki, K. (1964). Enzymatic determination and thin-layer chromatography of bile acids in blood. Journal of Biochemistry (Tokyo), 56, 424-431.

Leyland, F. C., Fosbrooke, A. S., Lloyd, J. K., Segall, M. M., Tamir, I., Tomkins, R., and Wolff, O. H. (1969). Use of medium-chain triglyceride diets in children with malabsorption. Archives of Disease in Childhood, 44, 170-179.

Murphy, G. M. (1975). Investigation of bile acid metabolism. Paediatric Gastroenterology, pp. 667-670. Ed. by C. M. Anderson and V. Burke. Blackwell, Oxford.

Redinger, R. N., Hermann, A. H., and Small, D. M. (1973). Primate biliary physiology. X. Effects of diet and fasting on biliary lipid secretion and relative composition and bile salt metabolism in the rhesus monkey. Gastroenterology, 64, 610-621.

Roller, R. J., and Kern, F., Jr. (1977). Minimal bile acid malabsorption and normal bile acid breath tests in cystic fibrosis and acquired pancreatic insufficiency. Gastroenterology, 72, 661-665.

Sherr, H. P., Nair, P. P., White, J. J., Banwell, J. G., and Lockwood, D. H. (1974). Bile acid metabolism and hepatic disease following small bowel bypass for obesity. American Journal of Clinical Nutrition, 27, 1369-1379.

Shwachman, H., Kulczycki, L. L., and Khaw, K-T. (1965). Studies in cystic fibrosis: a report on sixty-five patients over 17 years of age. Pediatrics, 36, 689-699.

Tyson, K. R. T., Schuster, S. R., and Shwachman, H. (1968). Portal hypertension in cystic fibrosis. Journal of Pediatric Surgery, 3, 271-277.

Van de Kamer, J. H., ten Bokkel Huinink, H., and Weijers, H. A. (1949). Rapid method for the determination of fat in feces. Journal of Biological Chemistry, 177, 347-355.

Watkins, J. B., Tercyak, A. M., Szczepanik, P., and Klein, P. D. (1974). Bile salt kinetics in cystic fibrosis. (Abst.) Gastroenterology, 67, 835.

Weber, A. M., Chartrand, L., Doyan, G., Gordon, S., and Roy, C. C. (1972). The quantitative determination of fecal bile acids in children by the enzymatic method. Clinica Chimica Acta, 39, 524-531.

Weber, A. M., Roy, C. C., Morin, C. L., and Lasalle, R. (1973). Malabsorption of bile acids in children with cystic fibrosis. New England Journal of Medicine, 289, 1001-1005.

Weber, A. M., Roy, C. C., Lepage, G., Chartrand, L., and Lasalle, R. (1975). Interruption of the enterohepatic circulation of bile acids in cystic fibrosis. (Abst.) Gastroenterology, 68, 1066.

Weber, A. M., Roy, C. C., Chartrand, L., Lepage, G., Dufour, O. L., Morin, C. L., and Lasalle, R. (1976). Relationship between bile acid malabsorption and pancreatic insufficiency in cystic fibrosis. Gut, 17, 295-299.

Webster, R., and Williams, H. (1953). Hepatic cirrhosis associated with fibrocystic disease of the pancreas; clinical and pathological reports of five patients. Archives of Disease in Childhood, 28, 343-350.

Correspondence to Dr C. A. Smalley, Institute of Child Health, Francis Road, Birmingham B16 8ET. 